\title{
Development and Validation of New Chromatographic Method for the Determination of Enantiomeric and Diastereomeric Purity of Solifenacin Succinate: An Antimuscarinic Agent
}

\author{
Shashikant B. Landge, ${ }^{1,2}$ Sanjay A. Jadhav, ${ }^{1}$ Sunil B. Dahale, ${ }^{1}$ Navanath C. Niphade, \\ Ch. Lakshmi Narayana, ${ }^{3}$ Vishwas B. Gaikwad, ${ }^{2}$ and Vijayavitthal T. Mathad ${ }^{1}$ \\ ${ }^{1}$ Research and Development, Megafine Pharma (P) Ltd., Nashik 422202, India \\ ${ }^{2}$ Department of Chemistry, Organic Chemistry Research Center, K.R.T. Arts, B.H. Commerce and A.M. Science College, \\ Gangapur Road, Nashik 422002, India \\ ${ }^{3}$ Daicel Chiral Technologies (India) Pvt. Ltd., Hyderabad 500078 AP, India
}

Correspondence should be addressed to Vijayavitthal T. Mathad, drvtmathad@yahoo.co.in

Received 27 July 2010; Accepted 27 September 2010

Academic Editor: Cristina Minguillón

Copyright (C) 2011 Shashikant B. Landge et al. This is an open access article distributed under the Creative Commons Attribution License, which permits unrestricted use, distribution, and reproduction in any medium, provided the original work is properly cited.

A new, simple, and rapid stereoselective normal phase-liquid chromatographic (NP-LC) method was developed to separate and quantify the solifenacin succinate and its three stereoisomers. The stereoisomeric separation was achieved on Chiralpak IC $(250 \times 4.6 \mathrm{~mm}$ ID) column. The mobile phase was consisting of $\mathrm{n}$-hexane, ethanol, isopropyl alcohol, and diethylamine in the ratio $(60: 15: 25: 0.1, \mathrm{v} / \mathrm{v} / \mathrm{v} / \mathrm{v})$, and the flow rate was maintained at $1.0 \mathrm{~mL} \mathrm{~min}^{-1}$. UV detection was carried out at $220 \mathrm{~nm}$. In addition, chiroptical detection was carried out using laser polarimeter to understand the elution orders. Resolution between all the stereoisomers was not less than 3. Effect of column temperature on resolution between the stereoisomers was studied. The method was validated as per ICH guideline and found to be robust. The proposed NP-LC method was successfully applied to the analysis of commercial formulation. The method could be of use not only for routine evaluation of the quality of solifenacin succinate in bulk drug manufacturing unit but also for detection of impurities in pharmaceutical formulations.

\section{Introduction}

Solifenacin, a well-known muscaranic receptor antagonist belongs to the anticholinergics used for the treatment of patients with overactive bladder such as urinary urgency, urinary incontinence, and high urinary frequency. It acts as a selective antagonist to the $\mathrm{M}(3)$ receptor and works by relaxing the bladder muscles to prevent urgent, frequent, or uncontrolled urination. It is available in the market under the brand name Vesicare in the form of tablets for oral administration containing 5 or $10 \mathrm{mg}$ of solifenacin succinate taken once daily [1-7]. Solifenacin succinate is the succinic acid salt of (3R)-1-azabicyclo[2.2.2] oct-3-yl-(1S)-1-phe- nyl-3,4dihydroisoquinoline-2(1H)-carboxylate having two chiral centers at $\mathrm{C} 1$ and $\mathrm{C} 3$ positions, and hence four possible stereoisomers do exist. Chemical structures of solifenacin and its three stereoisomers, namely (RS)-stereoisomer (isomer-1), (SS)-stereoisomer (isomer-2), and (RR)-stereoisomer (isomer-3), are shown in Figure 1. Stereoiso- mers of racemic drugs often differ in pharmacokinetic behavior or pharmacological action, and among the four stereoisomers, the pharmacological action of (SR)-stereoisomer, that is, solifenacin shows high affinity and selectivity for the M3 receptor and hence has been approved as the drug [8]. Recently, we reported the novel process for making highly stereoisomerically pure solifenacin succinate from our laboratory [9]. During the development, we felt the need for an efficient analytical method for the determination of stereoisomerical purity and the results of the same are reported here.

Development of an analytical method for the quantitative determination of stereoisomers in the drug substances/drug 
<smiles>O=C(O[C@H]1CN2CCC1CC2)N1CCc2ccccc2[C@H]1c1ccccc1</smiles>

(SR)-stereoisomer solifenacin

(a)<smiles>O=C(O[C@H]1CN2CCC1CC2)N1CCc2ccccc2[C@H]1c1ccccc1</smiles>

(SS)-stereoisomer (isomer-2) diastereomer of solifenacin

(c)<smiles>c1ccc([C@H]2NCCc3ccccc32)cc1</smiles>

Precursor-1

(e)<smiles>O=C(O[C@H]1CN2CCC1CC2)N1CCc2ccccc2[C@H]1c1ccccc1</smiles>

(RS)-stereoisomer (isomer-1) enantiomer of solifenacin

(b)<smiles>O=C(O[C@H]1CN2CCC1CC2)N1CCc2ccccc2[C@H]1c1ccccc1</smiles>

(RR)-stereoisomer (isomer-3) diastereomer of solifenacin

(d)<smiles>c1ccc(C2NCCc3ccccc32)cc1</smiles>

Precursor-2

(f)

FIgURE 1: Chemical structures of Solifenacin and its three stereoisomers and two precursors.

products having chiral centers is an important and challenging task during the drug synthesis and formulation research in pharmaceutical companies. It is highly essential to monitor and control other isomers to meet the stringent quality requirements. Although many analytical techniques like gas chromatography (GC), capillary electrophoresis (CE), and liquid chromatography (LC) can be employed for this purpose, liquid chromatography with a chiral stationary phase (CSP) is the most widely used technique [10-14]. Two methods are reported for the separation of stereoisomers in the solifenacin succinate $[15,16]$ using Chiralpak AD-H column (mobile phase comprising n-hexane:isopropyl alcohol: diethyl amine $(800: 200: 1, \mathrm{v} / \mathrm{v} / \mathrm{v})$; flow rate $1.0 \mathrm{~mL} / \mathrm{min}$; column temperature $20^{\circ} \mathrm{C}$; wavelength $220 \mathrm{~nm}$ ) and Chiralcel OD-H column (mobile phase comprising n-hexane: isopropyl alcohol: diethyl amine (500:8:1, $\mathrm{v} / \mathrm{v} / \mathrm{v})$; flow rate $1.0 \mathrm{~mL} / \mathrm{min}$; column temperature $40^{\circ} \mathrm{C}$; wavelength $230 \mathrm{~nm}$ ), respectively. With reported methods, we could not achieve the good resolution between Isomer-1 and Isomer-3 that leads to difficulty in the quantification, and the run time was found to be very long. Thus, we felt the need for a rapid and accurate stereoselective HPLC method to quantify all the stereoisomers of solifenacin. The efforts paid to develop the method to achieve better resolution between all the stereoisomers and solifenacin using different chiral stationary phases and chiroptical detection using laser polarimeter in our laboratory are presented in this paper. The developed method was validated to ensure the compliance in accordance with USP and ICH guideline $[17,18]$.

\section{Experimental}

2.1. Chemicals. Samples of solifenacin succinate, a mixture of all four stereoisomers of solifenacin and its three stereoisomers were received from synthetic laboratory, Megafine Pharma (P) Ltd., Nashik, India. HPLC grade n-Hexane, ethanol, and isopropyl alcohol were purchased from Qualigen fine chemicals, Mumbai, India. Diethylamine was purchased from Merck, Mumbai, India.

2.2. Equipment. The LC system used for method development and method validation was Agilent 1200 series 


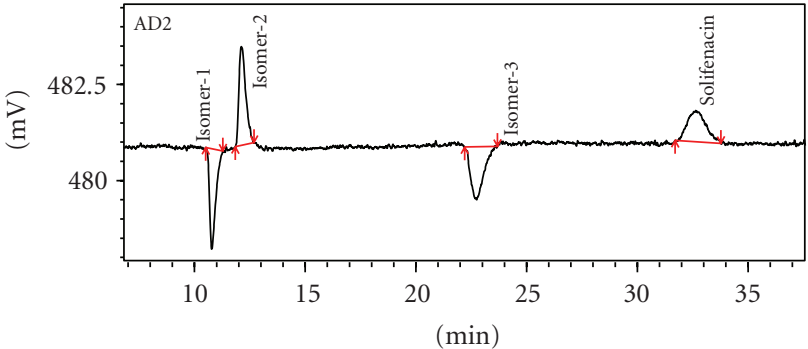

(a)

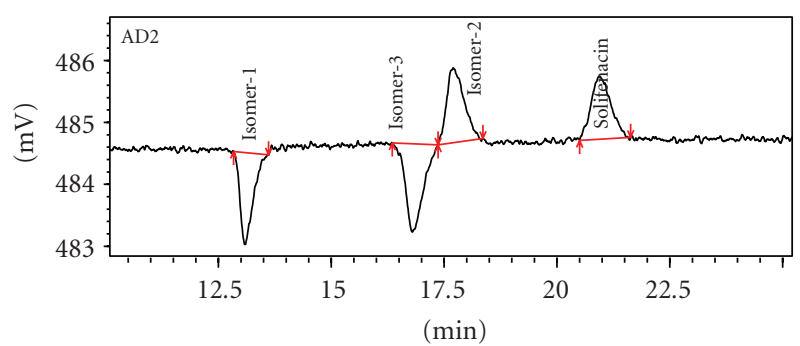

(b)

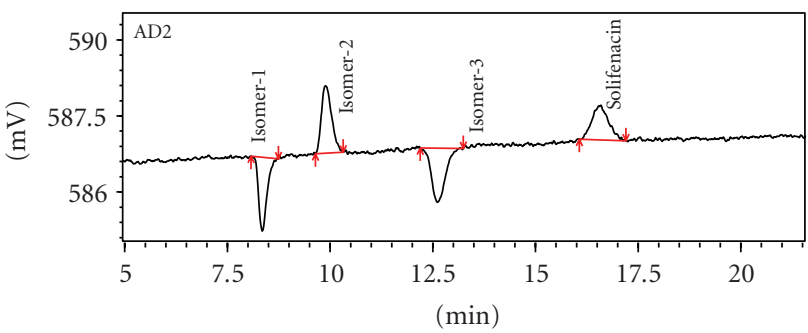

(c)

FIGURE 2: (a) Isomer elution order using n-Hexane:IPA:DEA $(70: 30: 0.1)$ mobile phase. (b) Isomer elution order using $n$ Hexane:EtOH :DEA ( $85: 15: 0.1)$ mobile phase. (c) Typical chromatogram representing isomeric separation of Solifenacin Succinate using n-Hexane: EtOH:IPA:DEA $(60: 15: 25: 0.1)$ mobile phase. (All trials have been conducted at column temperature $\left.25^{\circ} \mathrm{C}\right)$.

connected with a photodiode array detector (PDA) and variable wavelength detector (VWD). Chiral detection was performed using advanced laser polarimeter (PDR Chiral Inc.). The output signal was monitored and processed using EZChrome Elite software version 3.2.1. The chiral columns used during method development were Chiralcel OD-H, Chiralpak AD-H, Chiralpak-IA, Chiralpak-IB, and Chiralpak-IC (Daicel Chemical Industries, Japan) with $5 \mu \mathrm{m}$ particle size and $(250 \times 4.6 \mathrm{~mm}$ ID) dimension.

\subsection{Chromatographic Conditions}

2.3.1. Chromatographic Parameters. The chromatographic column used was a Chiralpak-IC, $250 \mathrm{~mm}$ length $\times$ $4.6 \mathrm{~mm}$ ID with $5 \mu \mathrm{m}$ particle size. The mobile phase was $n$-hexane: ethanol: isopropyl alcohol: diethyl amine $(60: 15: 25: 0.1, \mathrm{v} / \mathrm{v} / \mathrm{v} / \mathrm{v})$ pumped at a flow rate of $1.0 \mathrm{~mL} \mathrm{~min}^{-1}$. The column temperature was maintained at $30^{\circ} \mathrm{C}$, and the detection wavelength was $220 \mathrm{~nm}$. The test

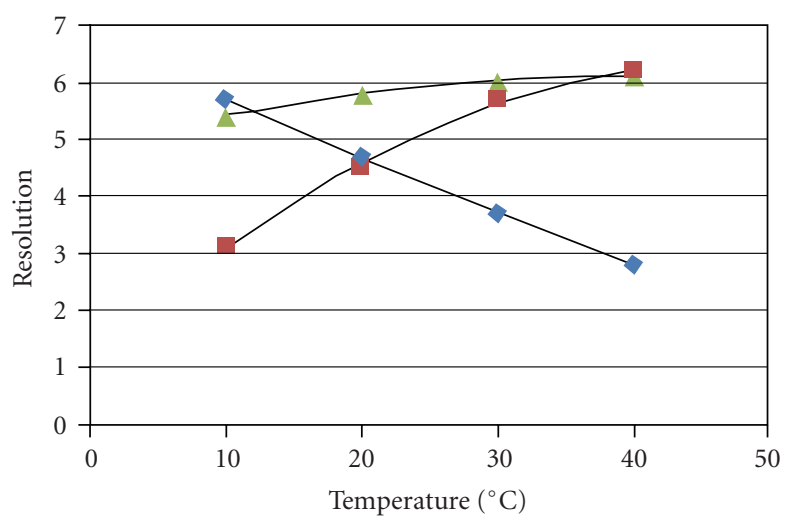

Rs1
- Rs2
- Rs3

FiguRE 3: Effect of column temperature on resolution between stereoisomers.

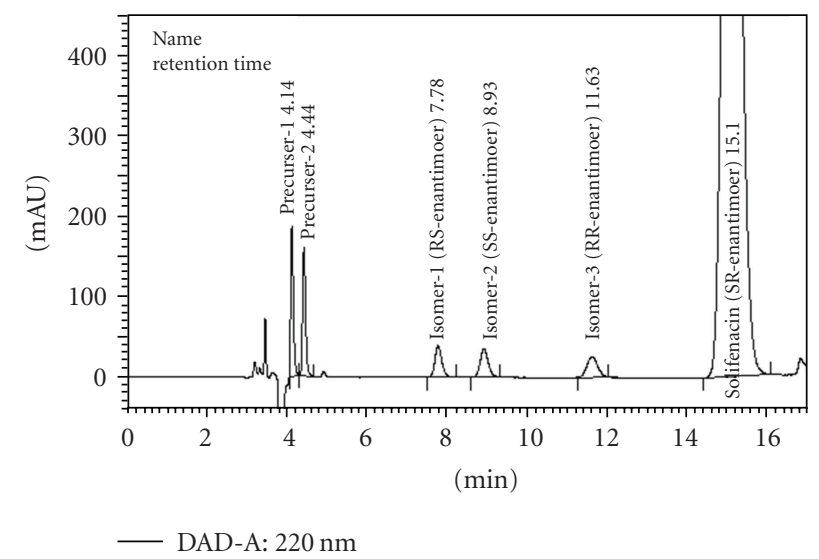

FIgURE 4: Method selectivity as illustrated by a typical chromatogram of solifenacin spiked with its precursor and stereoisomers at $0.15 \%$ level. (Chromatographic conditions- Chiralpak-IC, $250 \mathrm{~mm}$ $\times 4.6 \mathrm{~mm}$ ID column; mobile phase- $\mathrm{n}$-hexane : ethanol: isopropyl alcohol: diethyl amine $(60: 15: 25: 0.1, \mathrm{v} / \mathrm{v} / \mathrm{v} / \mathrm{v})$; flow rate $1.0 \mathrm{~mL} /$ min; column temperature $30^{\circ} \mathrm{C}$; wavelength $220 \mathrm{~nm}$ ).

concentration was about $1.0 \mathrm{mg} \mathrm{mL}^{-1}$, and the injection volume was $20 \mu \mathrm{L}$. Mobile phase was used as diluent during the standard and test sample preparation.

2.3.2. Preparation of Solutions. A mixture of all four stereoisomers standard solution of $6 \mu \mathrm{g} \mathrm{mL}^{-1}$ and test sample solution of $1000 \mu \mathrm{g} \mathrm{mL}^{-1}$ was prepared for the determination of stereoisomers. Individual stereoisomer solutions (isomer1 to 3 ) of $1.5 \mu \mathrm{g} \mathrm{mL}^{-1}$ were also prepared in diluent. Formulation drug sample was prepared as follows: ten weighed tablets of solifenacin succinate (equivalent to $5 \mathrm{mg}$ each of Solifenacin succinate) were ground to powder, and an equivalent of $25 \mathrm{mg}$ of active ingredient was dissolved in diluent in a $25-\mathrm{mL}$ volumetric flask, ultrasonicated for about $10 \mathrm{~min}$, and its volume was made up to the mark with the diluent, filtered through Merck Nylon syringe filter having 
pore size $0.45 \mu \mathrm{m}$. The clear liquid was collected and used for the determination of stereoisomers in the drug formulation.

\subsection{Analytical Method Validation Parameters}

2.4.1. Selectivity. The selectivity of the developed method was checked by injecting solifenacin succinate spiked with all stereoisomers and its precursor at $0.15 \%$ level with respect to target analyte concentration.

2.4.2. Precision. The precision of the method was carried out by injecting six individual preparations of solifenacin succinate spiked with $0.15 \%$ of all the stereoisomers (Isomer1 to Isomer-3) with respect to target analyte concentration (i.e., $1.0 \mathrm{mg} \mathrm{mL}^{-1}$ ). The percentages of stereoisomers in six different spiked test preparations were calculated. The RSD (\%) was calculated for each stereoisomer (Isomer-1 to Isomer-3) in each spiked test preparation.

The intermediate precision of the method was verified by performing the analysis on different day using different instrument number in the same laboratory by a different analyst. The results of method precision and intermediate precision were expressed in terms of percentage of stereoisomers in six spiked test preparations. The RSD (\%) for results of intermediate precision and results of method precision was calculated and compared with each other.

2.4.3. Limit of Detection (LOD) and Limit of Quantification (LOQ). The LOD and LOQ of all the three stereoisomers were determined using calibration curve method according to ICH Q2R1 recommendations by establishing the lowest concentration that can be measured with precision. Precision study was also carried out at the LOQ level by injecting six individual preparations of all the stereoisomers and calculating RSD (\%) of the area of each stereoisomer.

2.4.4. Linearity. The linearity of an analytical procedure is its ability (within a given range) to obtain test results, which are directly proportional to the concentration of the analyte in the sample. Linearity test solutions were prepared by diluting the stereoisomers stock solution to the required concentrations. The solutions were prepared at six concentration levels from LOQ to $500 \%$ with respect to the stereoisomers specification level of $0.15 \%$ (i.e., LOQ. 0.075 , $0.150 .0 .225,0.300,0.600$, and $0.750 \%$ related to solifenacin). The calibration curves for the stereoisomeric impurities were drawn by plotting the peak areas of stereoisomers versus its respective concentration. The correlation coefficient, intercept, and slope of the calibration curve were calculated and reported.

2.4.5. Accuracy. The accuracy of an analytical procedure expresses the closeness of agreement between the value, which is accepted either as a conventional true value or an accepted reference value and the value found. The recovery experiments were conducted to determine an accuracy of a developed HPLC method for the quantification of all three potential stereoisomeric impurities of solfenacin (Figure 1) in bulk drug samples. The study was carried out in triplicate at four concentration levels, that is, LOQ, 0.075, 0.15, and $0.225 \%$ of the analyte concentration $\left(1.0 \mathrm{mg} \mathrm{mL}^{-1}\right)$. The percentage recoveries were calculated by using formula (1):

$$
\% \text { Recovery }=\left(\frac{\text { Amount recovered }}{\text { Amount added }}\right) \times 100 \text {. }
$$

2.4.6. Robustness. To assess robustness of the method, the experimental conditions were deliberately altered, and resolution between the stereoisomers was evaluated. The effect of flow rate was studied at $0.9,1.0$, and $1.1 \mathrm{~mL} \mathrm{~min}^{-1}$. The effect of column temperature was studied at 27, 30, and $33^{\circ} \mathrm{C}$. The effect of mobile phase composition on resolution was assessed by changing the amounts of ethanol by $\pm 1 \%$. The effect of changing the amounts of the additive diethylamine was also studied. All the other mobile phase components were held constant as described in the section of chromatographic parameter.

\section{Results and Discussion}

3.1. Method Development and Optimization. To achieve the good separation between solifenacin succinate and its three stereoisomers, five chiral columns, namely Chiralpak AD-H, Chiralcel OD-H, Chiralpak IA, Chiralpak IB, and Chiralpak IC, were screened under normal phase conditions. Owing to the basic nature of the analyte, $0.1 \%$ DEA was added to the starting mobile phases n-Hexane/IPA (80/20, v/v) and n-Hexane/EtOH $(80 / 20, v / v)$. A mixture of all four stereoisomers of solifenacin succinate was used during the method development. Indication of separation between all the four peaks was noticed on all the columns except Chiralpak IB column. Method optimization experiments were performed using Chiralpak IC column due to its high selectivity compared to other columns screened under this study. Chiralpak IC is the latest column in the immobilized polysaccharide category of columns. Its chiral selector tris (3, 5-dichlorophenylcarbamate) was immobilised on silica gel and hence compatible with all kinds of solvents.

On Chiralpak IC column, retention times were found to be longer in case of IPA compared to ethanol as a modifier in the mobile phase. Interestingly, change in elution order was observed with change in alcohol modifier in presence of constant chromatographic conditions (i.e., flow rate, column oven temperature $25^{\circ} \mathrm{C}$, and injection volume). Chiroptical detection using laser polarimeter reveals the changes in elution order of stereoisomers. Elution order with IPA modifier and EtOH modifier was isomer-1, isomer-2, isomer-3, solifenacin and isomer-1, isomer-3, isomer-2, and solifenacin, respectively (Figures 2(a) and 2(b)). Reversal of elution order between isomer- 2 and isomer- 3 could be due to an alteration of the steric environment of the chiral grooves by alcohol modifier. Neither IPA nor EtOH as a separate modifier could not yield fast analysis time with satisfactory separation. By considering the fact that IPA and EtOH causing reverse elution order for isomer-2 and isomer-3, attempts were made by mixing both alcohol modifiers in the mobile phase. Fast elution with excellent 


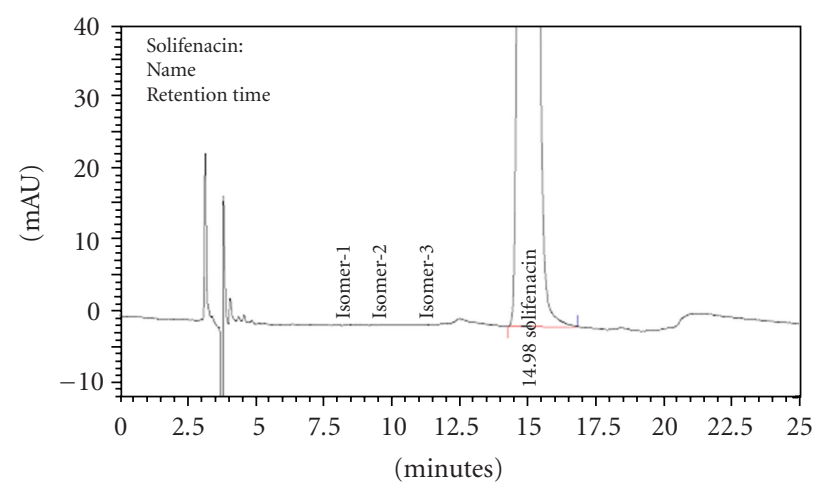

- DAD-A: $220 \mathrm{~nm}$

(a) Unspike test sample

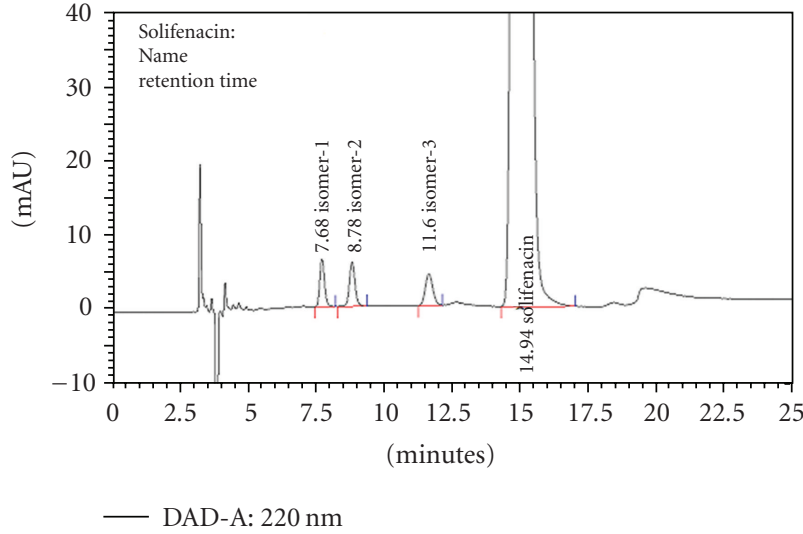

(b) Spike test sample

FIGURE 5: Typical chromatogram of solifenacin test sample, (a) unspiked and (b) spiked with stereoisomers at 0.15\% level.(Chromatographic conditions- Chiralpak-IC, $250 \mathrm{~mm} \times 4.6 \mathrm{~mm}$ ID column; mobile phase- $\mathrm{n}$-hexane:ethanol: isopropyl alcohol:diethyl amine $(60: 15: 25: 0.1, \mathrm{v} / \mathrm{v} / \mathrm{v} / \mathrm{v})$; flow rate $1.0 \mathrm{~mL} / \mathrm{min}$; column temperature $30^{\circ} \mathrm{C}$; wavelength $\left.220 \mathrm{~nm}\right)$.

TABle 1: Chromatographic characteristics of system suitability solution.

\begin{tabular}{lccc}
\hline \multirow{2}{*}{ Component } & \multicolumn{3}{c}{ System suitability parameter } \\
& Theoretical plate & Asymmetry & Resolution \\
\hline Isomer-1 & 9320 & 1.17 & - \\
Isomer-2 & 8627 & 1.18 & 3.2 \\
Isomer-3 & 7900 & 1.18 & 6.4 \\
Solifenacin & 7415 & 1.15 & 5.7 \\
\hline
\end{tabular}

separation was achieved using the mobile phase consisting of n-Hexane/EtOH/IPA/DEA in the ratio of $60: 15: 25: 0.1$, $\mathrm{v} / \mathrm{v} / \mathrm{v} / \mathrm{v}$ (Figure $2(\mathrm{c})$ ). The typical retention times of isomer1 , isomer-2, isomer-3, and Solifenacin were about 7.7, $8.8,11.6$, and $14.9 \mathrm{~min}$, respectively. The chromatographic characteristics were given in Table 1 .

Further, the effect of temperature on the resolution between all the stereoisomers was studied. Column temperature was maintained at $10,20,30$, and $40^{\circ} \mathrm{C}$ and the resolution was recorded (Figure 3 ). Resolution between isomer- 1 and isomer- 2 was decreased with increase in temperature; where resolution between isomer- 2 and isomer3 was increased with increase in temperature. Resolution between isomer-3 and solifenacin was not significantly affected with column temperature. The final optimized column temperature was maintained at $30^{\circ} \mathrm{C}$. The developed method was also applied to pharmaceutical formulations.

\subsection{Method Validation}

3.2.1. Selectivity. The selectivity of method was checked by injecting the test sample spiked with each individual stereoisomer and its precursor at $0.15 \%$ level of analyte concentration. An excellent separation between all the peaks was observed (Figure 4). Resolution between successive stereoisomer was found to be not less than 3.0 indicating good selectivity between solifenacin and all the stereoisomers. Hence, the method is selective to determine the stereoisomers of solifenacin succinate. Also, the selectivity for commercial formulation of solifenacin succinate was confirmed by injecting the tablet solution.

3.2.2. Precision. The RSD (\%) of content of isomer-1 to isomer-3 in method precision study was within $1.9 \%$ and in intermediate precision study was within $3.8 \%$. The results of method precision and intermediate precision were compared with each other. The overall RSD $(n=12)$ for percentage of stereoisomers (i.e., isomer-1 to isomer-3) was found within the range of $2.53 \%$ to $3.21 \%$. The precision results are reported in Table 2, confirming the good precision of the developed method.

3.2.3. $L O D$ and $L O Q$. The LODs of isomer-1, isomer-2 and isomer-3 were $0.003,0.002$, and $0.004 \%$, respectively (of analyte concentration i.e., $1.0 \mathrm{mg} \mathrm{mL}^{-1}$ solifenacin). The LOQs of isomer-1, isomer-2, and isomer-3 were 0.009, 0.007 , and $0.012 \%$, respectively (of analyte concentration i.e., $1.0 \mathrm{mg} \mathrm{mL}^{-1}$ solifenacin). The RSD (\%) of LOQ precision of all stereoisomers was NMT $10 \%$.

3.2.4. Linearity. Linear calibration plots were drawn for each stereoisomer (isomer-1, isomer-2, and isomer-3) ranging from LOQ to $500 \%$ of stereoisomer specification (NMT $0.15 \%$ ), and the correlation coefficient obtained was greater than 0.999 . These results demonstrate that an excellent correlation existed between the peak area and concentration of isomer-1 to isomer-3. The correlation coefficient, intercept, and slope for each stereoisomer is shown in Table 2.

3.2.5. Accuracy. The percentage recovery of stereoisomers (isomer-1 to isomer-3) in bulk drugs samples ranged from $93.3 \%$ to $104.6 \%$. The results of accuracy are reported in Table 2. HPLC chromatogram of all the three stereoisomers 
TABLE 2: Precision, linearity, and accuracy analysis results of solifenacin succinate.

\begin{tabular}{|c|c|c|c|}
\hline Validation components & Isomer-1 & Isomer-2 & Isomer-3 \\
\hline \multicolumn{4}{|l|}{ Precision } \\
\hline$\% \mathrm{RSD}$ in MP $(n=6)$ & 1.35 & 1.89 & 1.26 \\
\hline$\%$ RSD in IP $(n=6)$ & 3.42 & 3.80 & 3.27 \\
\hline Mean $\mathrm{x}^{-}(n=12)$ & 0.147 & 0.158 & 0.156 \\
\hline$\pm \mathrm{SD}(n=12)$ & 0.004 & 0.004 & 0.005 \\
\hline Overall \%RSD $(n=12)$ & 2.72 & 2.53 & 3.21 \\
\hline \multicolumn{4}{|c|}{ Linearity: LOQ to $500 \%$ of stereoisomer specification level } \\
\hline Correlation coefficient $(r)$ & 0.99955 & 0.99968 & 0.99947 \\
\hline Slope & 34545.27 & 33742.05 & 33984.35 \\
\hline Intercept & 592.75 & 1884.67 & 562.54 \\
\hline \multicolumn{4}{|c|}{ Accuracy (Mean Recovery $\pm \%$ RSD): LOQ to $150 \%$ of stereoisomer specification level } \\
\hline LOQ & $100.0 \% \pm 0.00 \%$ & $93.3 \% \pm 6.19 \%$ & $93.3 \% \pm 6.19 \%$ \\
\hline $50 \%$ & $104.6 \% \pm 3.34 \%$ & $100.4 \% \pm 2.00 \%$ & $101.7 \% \pm 1.95 \%$ \\
\hline $100 \%$ & $104.2 \% \pm 2.91 \%$ & $102.2 \% \pm 2.66 \%$ & $101.3 \% \pm 4.00 \%$ \\
\hline $150 \%$ & $103.2 \% \pm 0.78 \%$ & $102.5 \% \pm 2.84 \%$ & $102.5 \% \pm 0.25 \%$ \\
\hline
\end{tabular}

spiked in solifenacin bulk drug sample at specification level is shown in Figure 5(b).

3.2.6. Robustness. In all the deliberate varied chromatographic conditions (flow rate, column temperature, and composition), the resolution between successive stereoisomers was greater than 3.0, illustrating the robustness of the developed method.

3.2.7. Solution Stability. The solution stability of solifenacin succinate and its three stereoisomers was assessed by keeping the spiked sample solutions in a tightly capped volumetric flask at room temperature on a laboratory bench for $48 \mathrm{~h}$, calculating the amount of isomer-1, isomer-2, and isomer-3 at every $6 \mathrm{~h}$ intervals and comparing with freshly prepared solution. The solution stability experiment data confirms that sample solutions prepared in the mobile phase were stable up to $48 \mathrm{~h}$ at room temperature $\left(25^{\circ} \mathrm{C}\right)$.

3.3. Application of Method. The analysis results of the commercial formulation sample and bulk drug sample are shown in Table 3. It indicates that the method is specific and selective for the determination of stereoisomers of solifenacin succinate in the formulation and bulk drug samples. The typical chromatogram of batch sample analysis is also shown in Figure 5(a).

\section{Conclusions}

The method presented in this communication describes the development of a rapid, simple, and accurate HPLC method that separates all four stereoisomers (isomer-1, isomer2 , isomer-3, and solifenacin) with good resolution. The developed method was validated to ensure the compliance in
TABLE 3: Results (\%) of formulation tablet analysis and bulk drug batches sample analysis.

\begin{tabular}{|c|c|c|c|}
\hline Sample source & Isomer-1 & Isomer-2 & Isomer-3 \\
\hline \multicolumn{4}{|c|}{ Formulation product analysis results } \\
\hline Formulation-1 & Not detected & 0.10 & Not detected \\
\hline Formulation-2 & Not detected & 0.05 & Not detected \\
\hline \multicolumn{4}{|c|}{ Batch analysis results (\%) } \\
\hline B.NO.SOL/A107/I/03 & Not detected & 0.01 & Not detected \\
\hline B.NO.SOL/A107/I/04 & Not detected & 0.01 & Not detected \\
\hline B.NO.SOL/A107/I/05 & Not detected & 0.01 & Not detected \\
\hline
\end{tabular}

accordance with ICH guideline. The developed method will be useful for monitoring the quantitative determination of stereoisomers in the bulk and formulation samples.

\section{Acknowledgments}

The authors wish to thank the management of Megafine Pharma for supporting this paper. They also thank colleagues in the Research and Development department, Megafine Pharma (P) Ltd., for their cooperation in carrying out this work. Further, the authors wish to acknowledge the contribution of Mr. K. Vijaya Bhaskar, Research Associate of Daicel Chiral Technologies (India) Pvt Ltd., for his valuable experimental work.

\section{References}

[1] L. Cardozo, M. Lisec, R. Millard et al., "Randomized, doubleblind placebo controlled trial of the once daily antimuscarinic agent solifenacin succinate in patients with overactive bladder," Journal of Urology, vol. 172, no. 5, pp. 1919-1924, 2004. 
[2] R. A. Smulders, W. J. Krauwinkel, P. J. Swart, and M. Huang, "Pharmacokinetics and safety of solifenacin succinate in healthy young men," Journal of Clinical Pharmacology, vol. 44, no. 9, pp. 1023-1033, 2004.

[3] T. Yanagihara, T. Aoki, Y. Soeishi, T. Iwatsubo, and H. Kamimura, "Determination of solifenacin succinate, a novel muscarinic receptor antagonist, and its major metabolite in rat plasma by semi-micro high performance liquid chromatography," Journal of Chromatography B, vol. 859, no. 2, pp. 241245, 2007.

[4] A. Wagg, J.-J. Wyndaele, and P. Sieber, "Efficacy and tolerability of solifenacin in elderly subjects with overactive bladder syndrome: a pooled analysis," American Journal Geriatric Pharmacotherapy, vol. 4, no. 1, pp. 14-24, 2006.

[5] K. Ikeda, S. Kobayashi, M. Suzuki et al., "M3 receptor antagonism by the novel antimuscarinic agent solifenacin in the urinary bladder and salivary gland," Naunyn-Schmiedeberg's Archives of Pharmacology, vol. 366, no. 2, pp. 97-103, 2002.

[6] M. C. Michel, M. Oelke, and N. Zinner, "Novel muscarinic antagonists to treat incontinence and/or overactive bladder," Drug Discovery Today: Therapeutic Strategies, vol. 2, no. 1, pp. 1-6, 2005.

[7] http://www.medilexicon.com/drugs/vesicare.php.

[8] R. Naito, Y. Yonetoku, Y. Okamoto, A. Toyoshima, K. Ikeda, and M. Takeuchi, "Synthesis and antimuscarinic properties of quinuclidin-3-yl 1,2,3,4-tetrahydroisoquinoline-2carboxylate derivatives as novel muscarinic receptor antagonists," Journal of Medicinal Chemistry, vol. 48, no. 21, pp. 6597-6606, 2005.

[9] N. C. Niphade, K. M. Jagtap, A. C. Mali, P. V. Solanki, M. N. Jachak, and V. T. Mathad, "Efficient and single pot process for the preparation of enantiomerically pure solifenacin succinate: an antimuscarinic agent," Monatshefte Fur Chemie. In press.

[10] http://www.chiraltech.com/app/IC_0607.pdf.

[11] P. Franco and T. Zhang, "Common approaches for efficient method development with immobilised polysaccharidederived chiral stationary phases," Journal of Chromatography $B$, vol. 875, no. 1 , pp. 48-56, 2008.

[12] T. Zhang, D. Nguyen, and P. Franco, "Enantiomer resolution screening strategy using multiple immobilised polysaccharidebased chiral stationary phases," Journal of Chromatography A, vol. 1191, no. 1-2, pp. 214-222, 2008.

[13] T. Zhang, D. Nguyen, P. Franco, Y. Isobe, T. Michishita, and T. Murakami, "Cellulose tris(3,5-dichlorophenylcarbamate) immobilised on silica: a novel chiral stationary phase for resolution of enantiomers," Journal of Pharmaceutical and Biomedical Analysis, vol. 46, no. 5, pp. 882-891, 2008.

[14] H. Y. Aboul-Enein, "High-performance liquid chromatographic enantioseparation of drugs containing multiple chiral centers on polysaccharide-type chiral stationary phases," Journal of Chromatography A, vol. 906, no. 1-2, pp. 185-193, 2001.

[15] I. Masatoshi, "Process for prodcuing solifenacin or its salt," EP. Pat., 1757604 A1, 2007.

[16] P. Jordi, S. Laura, M. Ester, A. Ignasi, and B. Jordi, "An improved process for the synthesis of solifenacin," WO 2008/062282 A2, 2008.

[17] The United States Pharmacopeia, Validation of Compendial Methods, USP, Rockville, Md, USA, 32nd edition, 2009.

[18] International Federation of Pharmaceutical Manufactures \& Associations (IFPMA), "Validation of analytical procedure," in Proceedings of International Conference on Harmonization (ICH '96), Geneva, Switzerland, 1996, Methodology Q2(R1). 


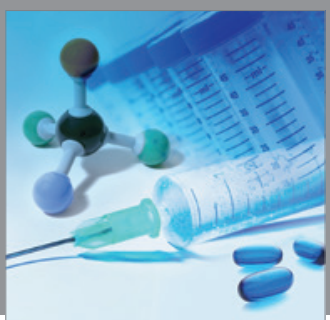

International Journal of

Medicinal Chemistry

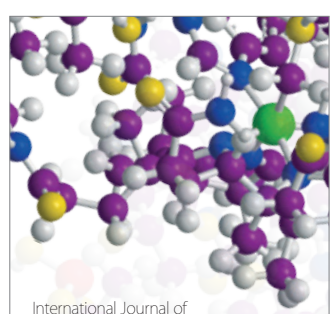

Carbohydrate Chemistry

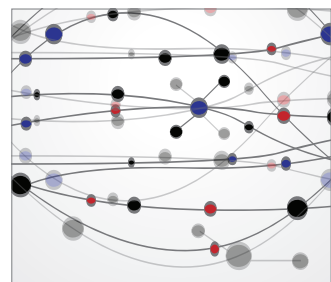

The Scientific World Journal
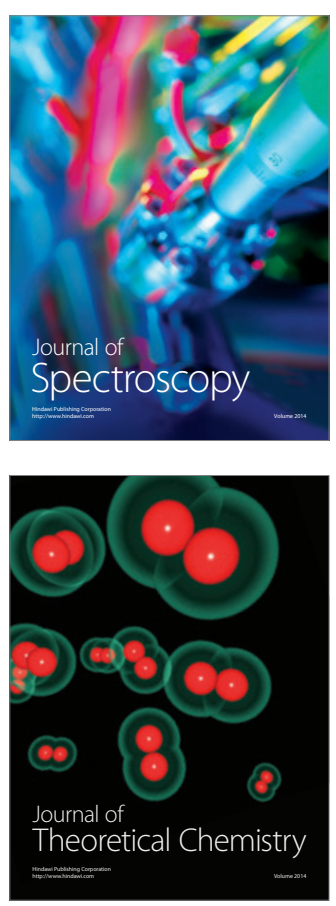
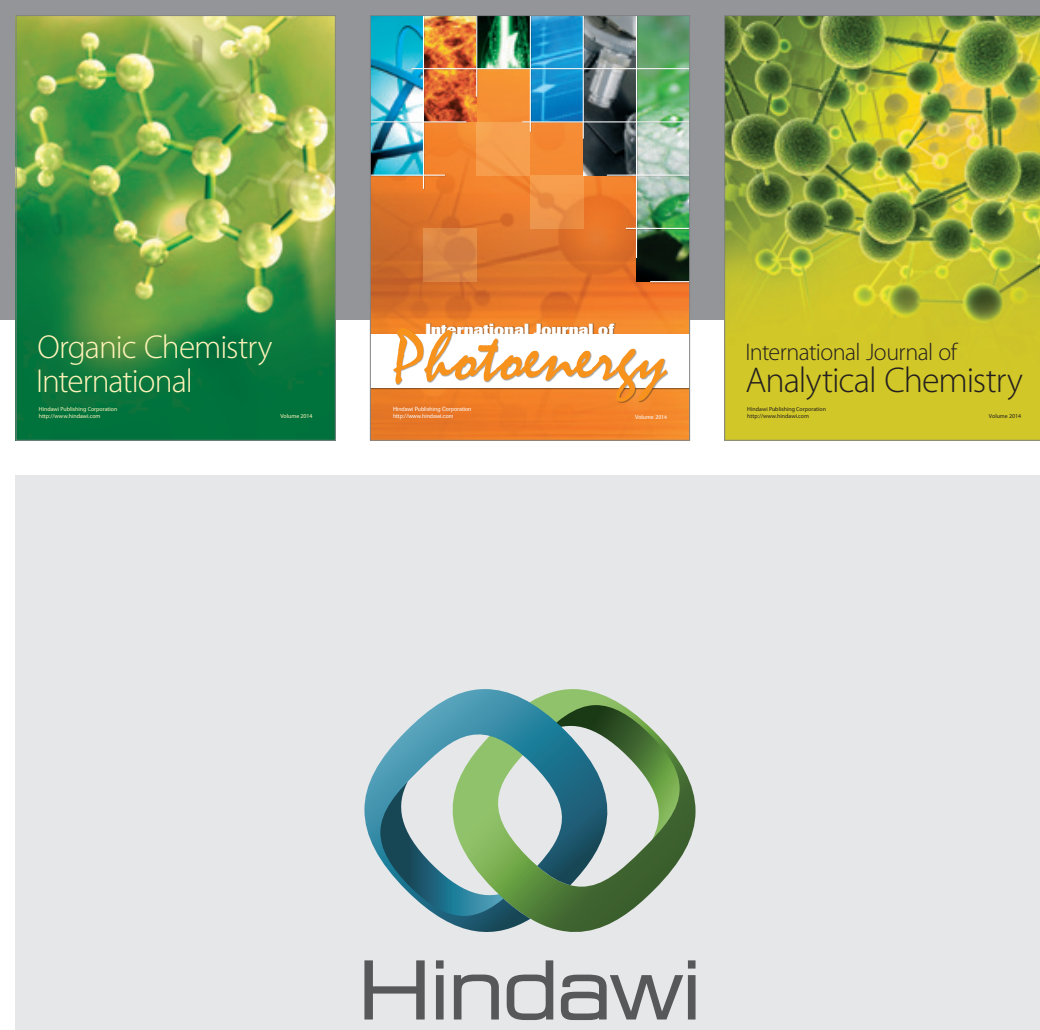

Submit your manuscripts at

http://www.hindawi.com
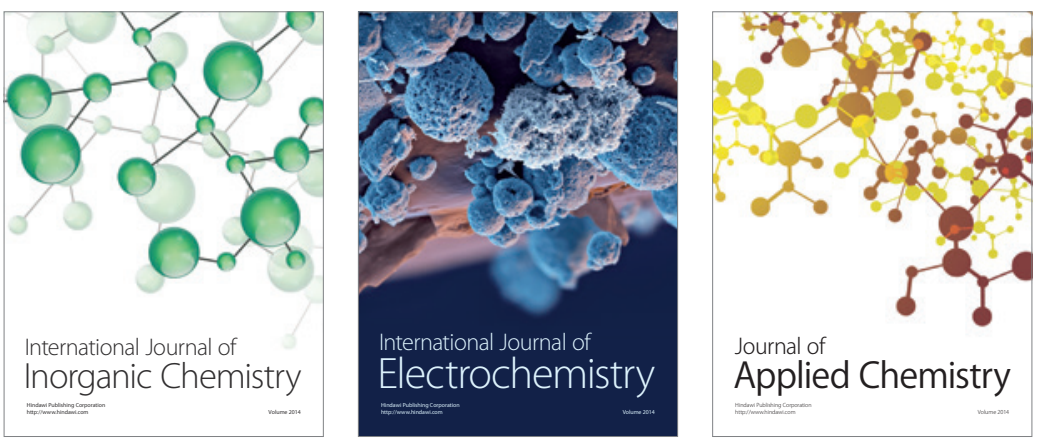

Journal of

Applied Chemistry
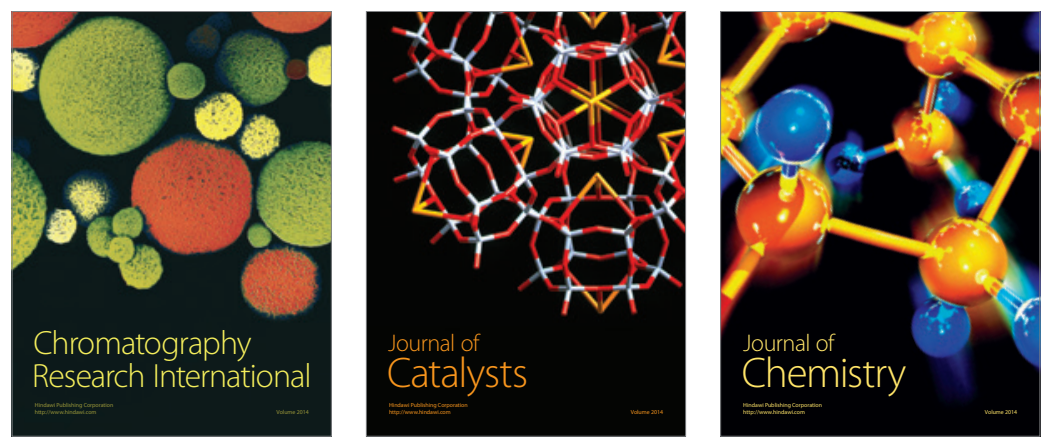
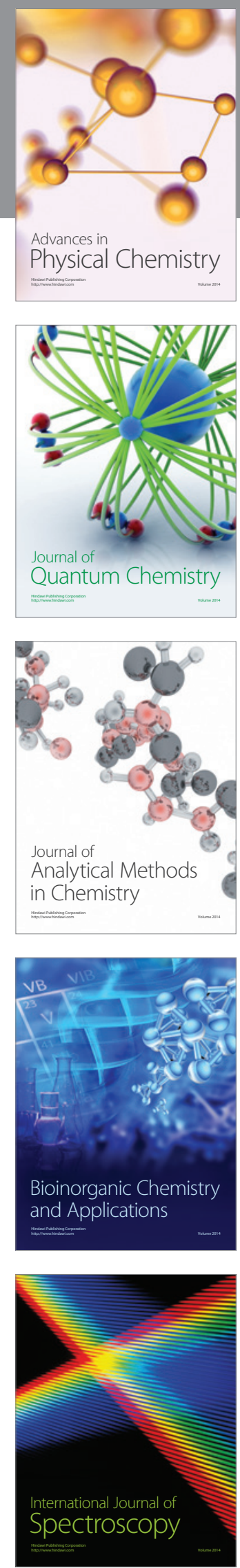